
\title{
28 Research Suare \\ Development of a Prognostic Model for 1-year Survival of Fragile Hip Fracture in Chinese
}

\section{Hairui FU}

Third Hospital of Shanxi Medical University https://orcid.org/0000-0002-4750-8798

\section{Bin Liang}

Affiliated Fenyang Hospital of Shanxi Medical University

\section{Wei Qin}

Affiliated Fenyang Hospital of Shanxi Medical University

\section{Xiaoxiong Qiao}

Affiliated Fenyang Hospital of Shanxi Medical University

Qiang Liu ( $\nabla$ sxdyy001@163.com )

Third Hospital of Shanxi Medical University https://orcid.org/0000-0003-3757-0384

\section{Research article}

Keywords: Prognostic model, Development, Fragile hip fracture, Survival

Posted Date: August 30th, 2021

DOI: https://doi.org/10.21203/rs.3.rs-820784/v1

License: (c) (1) This work is licensed under a Creative Commons Attribution 4.0 International License. Read Full License 


\section{Abstract}

Background: No prognostic model for survival of fragile hip fracture has been developed for Asians. The goal of this study is to develop a simple and practical prognosis model to predict the survival within 1 year after fragile hip fracture of Asians.

Methods: A single Center and retrospective cohort study was designed. Under a multivariable Cox Proportional Hazards Regression Model, we used the preoperative characteristics of patients to predict survival within 1 year after hip fracture. We built a full model, then used the "least absolute shrinkage and selection operator(LASSO)" method to further shrink the model coefficients and achieved variable screening. Finally, we got a LASSO model. The model performance was evaluated with the Nagelkerke's R2 and the concordance (c) statistic. We assessed internal validity with a bootstrapping procedure of 1 000 repetitions.

RESULTS: 735 eligible patients were admitted to our department for hip fracture from January 2015 to December 2020. 11(1.5\%) patients lost follow-up. Among the rest, 68(9.3\%) died within 1 year after hip fracture. We finally identified 12 candidate predictors from preoperative characteristics of patients. The last model contains 9 predictors; that are surgery, age, albumin, sex, serum creatinine, malignancy, hypertension, the ability of living independence, and cardiovascular and cerebrovascular diseases. Among them, surgery, age and albumin are the effective predictors of survival. The discrimination c statistic of the model is 0.814 (95\% confidence interval $0.762-0.865)$; the corrected value through internal validation is 0.795 .

CONCLUSIONS: This prognostic model can provide a 1-year survival rate for patients with fragile hip fractures. This information can help clinicians develop a reasonable and personalized treatment plan.

\section{Introduction}

\section{Background and Objectives}

Fragile hip fractures mainly occur in middle and old age patients, especially elderly patients. These patients tend to have more medical complications. It is not uncommon for them to die shortly after discharge or even during hospitalization. This poses a challenge for orthopedic surgeons and patients in choosing treatment options. For example, for patients who die shortly after surgery, their family members may think that the doctor's recommendation to choose surgery is wrong; conservative treatment may be more appropriate, whether in terms of economic benefits or survival time. How to use the preoperative characteristics of patients to distinguish the high-risk patients who die shortly after hip fracture from the low-risk patients quickly, and thus to inform doctor and family member of the patient's prognosis in advance, is of great practical significance both in providing personalized treatment and alleviating the doctor-patient contradiction. 
A small number of existing similar models[1-7]have many problems. Firstly, some models take other models as predictors. This makes the model complex and difficult to understand. It inevitably reduces their practicality [4-6]. For example, one model contains only six predictors, three of which are the models[5]. Secondly, some models use outcome variables as predictors, such as postoperative complications. This greatly reduces the meaning of their existence[1].Furthermore, there are methodological shortcomings: Improper selection of the statistical model. For instance, studying survival outcomes with logistic regression model[5]; studying binary outcomes with linear regression model[2]. Converting all continuous variables into categorical variables $[3,6]$, resulting in lower information utilization. Not correcting overfitting[6]. Determining candidate predictors with univariate analysis[6]. Finally, no similar model has been developed for Asians.

The goal of this study is to develop a simple and practical prognosis model for Asians, using simple and easy-to-obtain preoperative characteristics to predict the Survival within 1 year after Fragile Hip Fracture (SFHF). This model is mainly aimed at clinicians. They can quickly predict the risk of death of patients based on this model before taking surgery. This provides a reference for both doctors and patients to jointly develop a reasonable personalized treatment.

The principle of model development is that practicality takes precedence over accuracy.

\section{Methods}

The report for this paper follows the TRIPOD Statement[8].

\section{Source of Data}

The data came from a retrospective cohort study designed specifically for the development of this model. The study was conducted at Fenyang Hospital, a general university hospital in Shanxi Province, China. The participants of the model were the patients who had been admitted consecutively to the orthopedics department of the hospital for hip fractures from January 2015 to December 2020. The follow-up started on April 13, 2021 and ended on May 28, 2021.

\section{Participants}

Our hospital is a municipal tertiary hospital and its patients mainly come from surrounding counties and cities. Inclusion criteria were: $\triangle A g e \geq 50$ years old. The author chose 50 as the cut-off point in order to include as many fragile hip fracture patients as possible, especially for some women whose Fragile fractures occur earlier than others'. $\otimes$ Fragile fracture. Fragile fractures or low-energy fractures (considered as synonyms here) refer to that hip fractures happen when patients falling from standing height or lower. For example, falling when walking or when standing up or sitting down. Exclude high-energy fractures such as high fall, traffic accident, heavy pound injury, fights and so on. Hip fractures here include femoral 
neck, intertrochanteric and subtrochanteric fractures.

Periprosthetic and pathological fractures were also excluded.

In our hospital, the basic process after a patient admitted is: She/he is considered for surgical treatment initially and complete routine preoperative tests such as necessary laboratory tests, fracture sites and chest X-rays. If the patient has a medical disease, invite the relevant departments for consultation and give symptomatic treatment. With the consent of the patient, surgery is performed as soon as possible after stabilizing the patient's general condition. Such a scheme results in very few patients performing surgery within 24 hours of hospitalization. Conservative treatment shall be adopted if the doctor believes that the patient cannot tolerate surgery, or if the patient himself/herself refuses the procedure. The general choice of surgical treatment methods is: femoral neck fracture- 3 hollow nail fixation ( $<65$ years old) or half hip or total hip replacement ( $\geq 65$ years old); intertrochanteric or subtrochanteric fractureproximal femur intramedullary nail fixation.

\section{Outcome:}

Outcome of interest was any cause deaths within 1 year after hip fracture. It was determined through telephone interviews. All interviews were conducted after patient data had been collected.

To ensure a high successful follow-up rate, we have made the following efforts. खDeveloped the principle of telephone interviews: minimized the content of interviews as much as possible. Interview content varied according to the different conditions of patients. In addition to collecting death and time information, it also increased the cause of death, the patient's self-care ability before the fracture and/or after recovery. The purpose was to make the interview easier to be accepted by the family. According to the treatment methods in our hospital, patients were divided into surgical and conservative two categories. For the former, if the patient died, asked about the time of death, the reason, and the self-care situation before the fracture; if survive, asked about the current self-care situation; if the patient could take care of himself/herself now, end the interview; otherwise continued to ask about the self-care situation before the fracture. For the latter, they could not simply be classified as conservative treatment, for they might go to other places for surgery after leaving our hospital. So, we must first determine whether they had been keeping conservative treatment; if so, asked like the patients taking surgery in our hospital; If not, they were classified as surgical patients and also asked like the patients taking surgery in our hospital besides one more question- operation time. In this way, at least one question would be asked in each interview. For example, those who had recovered their self-care ability after surgery can end the interview after just asking about their current recovery status. At most 5 questions be asked.

For example, those died after going to other hospitals for surgery, \whether they were operated after

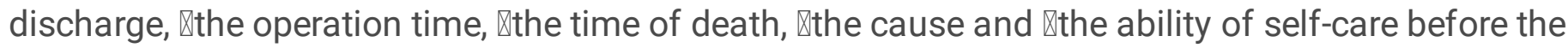
fracture(Figure 1). $\nabla$ Set up time reference points to help patients' families recall when the death had occurred. For example, asking the family members of the patients who go on surgery after discharge, " Which day after discharge or fracture the surgery was performed ". For the patients who had died but their 
family members could not recall the specific time of death, using a method of narrowing the time range gradually. For example, "Which season did the death occur? Before or after the Spring Festival? Had it passed the Lantern Festival?" $\triangle$ In the cases of a wrong telephone call, or the family could not determine the specific time of death, or unwilling to cooperate, we would return to the original medical record, checking the telephone number, or looking for the other telephone numbers recorded, then reinterviewed. $\otimes$ When the original medical records were checked and the interviews were still unsuccessful, we turned to the community medical system, which registered the telephone numbers of all families living in the community. If got a new phone number and then interviewed again.

Through the above methods, most of the first time lost to follow-up could successfully get in touch. The rest would be regarded as missing data.

\section{Predictors:}

Based on the principle of modeling (practicality is preferred to accuracy) and the purpose (to provide a reference for formulating a treatment plan), we determined the principle of selecting candidate predictors: $\triangle$ Simplicity. Select predictors from the patient's medical history and routine preoperative preparations. QStability. Choose predictors measured relatively sF across different testers or patients. \lndependence. Select predictors that can be determined independently by an orthopedic surgeon, without consultation with other departments. $\triangle$ Rapidity. The results of the predictors are determined quickly within 24-48 hours after admission, without long waits. $\otimes$ Quantitative indicators prioritize qualitative indicators. $\otimes$ Relevance. Select relevant factors that affect the implementation of surgical treatment. $\otimes$ Subject matter knowledge. Select the indicators that have been shown to be relevant to survival rates.

Initially, 24 indicators were extracted for each patient to provide readers with detailed sample characteristics. Including: General characteristics: medical insurance, age(Age), sex(SEX); Disease characteristics: fracture site, fracture type, time from fracture to hospitalization, time from hospitalization to surgery, length of stay (LOS); Medical history: diabetes, hypertension(HYP), malignancy(MAL), kidney disease $(K D)$, lung disease(LD) on admission, the ability of living independence(ALI) before fracture, cardiovascular and cerebrovascular diseases(CCD);Test results $\llbracket$ all use the first test value after admission囚: partial pressure of oxygen $\left(\mathrm{PaO}_{2}\right)$, fasting blood sugar (BS), serum creatinine (SC), hemoglobin ( $\mathrm{Hb}$ ), total protein (TP), albumin (ALB); mean arterial pressure (MAP); Treatment: skeletal traction. In order to understand the impact of surgery (SUR) on survival, SUR was deliberately used as a predictor though it not a preoperative indicator.

Some of the indicators were defined as follows: $₫$ Medical insurance: It includs employee medical insurance and non-employee medical insurance. China has achieved a full medical insurance coverage since 2011. Non-employee medical insurance mainly includes new rural cooperative medical insurance, a small number of other types of commercial insurance, and self-paid medical treatment. On the whole, type of medicare can reflect the economic situation of a patient from the side. $\otimes$ Fracture site: Including the femoral neck, intertrochanteric and subtrochanteric. $\otimes$ Fracture type: It contains primary and 
secondary fracture two types. If there had been fragility fractures before this fracture, such as the most common osteoporotic vertebral compression fractures, hip fractures, wrist fractures, and proximal

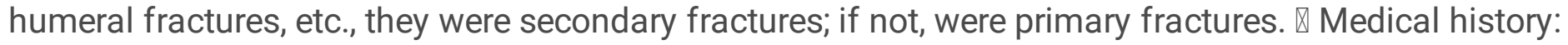
Whether a patient had been diagnosed with diabetes, HYP, MAL or KD was obtained from the medical records, that were provided by the patient and/or his/her family when he/she was admitted to the hospital. $\mathbb{\text { LD }}$ on admission: It contains positive and negative. Positive are various types of pneumonia, tuberculosis, pleural effusion and/or structural changes such as pulmonary bullae and fibrosis, but do not include local stability small lesions, such as stable calcifications. They were determined by chest Xray or chest CT. Otherwise, negative. In particular, this indicator did not include lung tumor which was classified as MAL. $\triangle$ ALI: Positive mainly means that the patient could not walk independently and complete the basic activities of daily life without the help of others before fracture. This results from various reasons, including sequelae of cerebrovascular events, severe hip or knee arthritis, Alzheimer's disease or severe depression, etc. Otherwise, negative. $\triangle$ CCD: Positive for this indicator means that the patient had been diagnosed with diseases such as myocardial infarction, cerebral infarction, and cerebral hemorrhage; or the CT and/or MRI examination of the head after admission showed the presence of old local infarct changes. In addition, it also includes the intravascular thrombosis shown by the vascular ultrasound examination of the extremities, but do not include atherosclerotic plaque formation, stenosis and other changes. These examinations were not routine examinations after patients admitted. If a patient did not take these tests, and have no history of diagnosis of the above-mentioned cardiovascular and cerebrovascular diseases, she/he was regarded as negative. $\otimes \mathrm{PaO}_{2}, \mathrm{BS}, \mathrm{SC}, \mathrm{Hb}, \mathrm{TP}, \mathrm{ALB}$ : These 6 indicators were routine laboratory test items after admission. Generally, specimens were collected at 7 o'clock in the morning on the second working day after admission, and all the results would be reported in the afternoon. $₫$ MAP: It is obtained by $1 / 3$ systolic blood pressure plus $2 / 3$ diastolic blood pressure. This value came from the vital signs' examination of a patient performed immediately after admission. $\otimes$ Skeletal traction: In general, skeletal traction was considered on the day of admission. If patients refused, or if it was determined that surgical treatment would be forthcoming the next day, gave up bone traction. Almost all patients given this treatment were tibial tuberosity traction.

Based on the above predictor screening principles, we reduced the number of candidate predictors. We excluded medical insurance, fracture site, fracture type, time from fracture to hospitalization, time from hospitalization to operation, and skeletal traction. Because no matter what the results of these indicators are, they do not affect the choice of surgical treatment. According to the principle of priority to quantitative indicators, exclude diabetes, kidney disease, selected BS, and SC. Although MAP is a quantitative variable, it is easily affected by various factors and poor stability, so we chose HYP. There is some overlap between serum TP and ALB. Studies $[9,10]$ have shown that low ALB was a prognostic factor for death after fracture, so TP was excluded. Based on the principle of stability, $\mathrm{PaO}_{2}$ was excluded. Because many elderly patients were often given oxygen immediately after admission, and it was difficult to strictly follow the doctor's instructions to stop oxygen inhalation two hours before measuring the index, making it very unstable across patients. As a result, 12 candidate predictors were determined, including Age, SEX, MLA, LD, ALI, CCD, SUR, BS, SC, Hb, ALB and HYP. 


\section{Sample Size}

We did not specifically calculate the sample size required. The reason is that sample size is affected by many factors, and there is no well-known calculation method[11-13]. Secondly, in reality, we cannot easily expand a single-center study into a multi-center trial or arbitrarily extend research time to increase sample size.

According to widely accepted empirical guidelines, we strived to achieve at least 10 events per variable (EPV), or at least a total of 100 events in the sample. Fortunately, many empirical studies can guide how to develop predictive models based on a small sample[14, 15].

\section{Missing Data}

The characteristics of missing data are shown in Figure 2.

Among the 14 variables (2 outcome variables, death(Y)and time, and 12 covariates), there were 8 variables with missing values, including SUR (containing 9 missing values), BS (9), SC (9), Hb (9), ALB (13), LD (58), Y (11) and time (11). 660 observations had no missing, a maximum of 5 variable values were missed in 5 observations.

Whether the missing data came from covariates or outcome, we used the mice package for Single Imputation (SI) in R software. Although Multiple Imputation (MI) could be used, the reasons why we chose SI are as follows: First, we had relatively few missing. Among all the variables with missing values, LD had the highest missing rate, which was $7.9 \%$, and the missing rates of the remaining variables were less than $2 \%$. Second, a SI data set can be easily created from the first of a series of MI data sets, and it avoids the complicated combining over multiple MI data sets[16]. Third, no method has been found to combine LASSO models derived from multiple MI data sets[17]. Finally, empirical research shows that the estimation of model regression coefficients is very consistent between the SI data set and the MI stacked data set[18].

Because our SI data set came from the first of the MI data series, we also analyzed the missing mechanism of the data and explained the method of generating the MI data series. The missing data was mainly related to the choice of treatment methods for patients. When patients and their families were not active or even skeptical about surgical treatment, they often refused any routine preoperative preparations. In this case, several variable values were often missing together. Therefore, missing data was often seen in patients who took conservative treatment. This is a "missing at random" (MAR) situation, and MI can effectively deal with this problem[19-21].The 12 candidate predictors and the outcome of event and time were all included in the imputation procedure. In this way, 8 variables, LD, SUR, BS, SC, Hb, ALB, Y and time, were imputed. Among them, the two factor variables, LD and SUR, were imputed using the logistic regression (logreg) method, while the remaining 6 variables were imputed 
using the predictive mean matching $(\mathrm{pmm})$ method. No interaction terms were introduced during the MI procedure.

\section{Statistical Analysis Methods}

The distributions of the 5 continuous variables Age, BS, SC, Hb and ALB of the 12 candidate predictors were checked for extreme values. After excluding input errors, only SC was found to have obvious extreme value. The extreme values of SC were winsorized

to avoid excessive leverage effects. It was done by shifting the values above 99th centile(8 values, of them the maximum was $860 \mu \mathrm{mol} / \mathrm{L}$ ) to truncation points(99th centile, $190.75 \mu \mathrm{mol} / \mathrm{L}$ ).

To make full use of the information, we did not categorize any continuous variables and all kept their original scales. For all continuous variables, linear and non-linear relationship with outcome were fitted. The nonlinear were fitted by using Restricted Cubic Splines (RCS), and 3, 4, and 5 knots were compared for each variable. In particular, we also checked the log transformation for SC. In addition, we plot the relationship between the fitted variables and the outcome to check the biological rationality. Based on a higher Wald $\chi 2$ value but a lower degree of freedom(df) and

biological rationality, the final coding of each number variable in the model was determined (Table 1). The optimal coding for each predictor were: Age: linear; BS: non-linear (RCS,3 knots); SC: linear; Hb: nonlinear (RCS,3 knots); ALB: linear.

According to the principle of simplicity of modeling, all the seven categorical variables of SEX, MLA, LD, ALI, CCD, HYP and

\section{Type of model}

Because our goal was a 1-year survival rate, a time-to-event outcome, we chose the Cox proportional hazards model.

\section{Predictor selection during modeling}

Based on our small sample and empirical studies[14, 15, 22, 23] shown that the stepwise selection deteriorates the predictive quality of the model in small data sets, we chose to build a full model that included all 12 candidate predictors. We would further refine the full model using the LASSO method 


\begin{tabular}{|c|c|c|c|c|c|}
\hline Optimal c & loration $\mathrm{f}$ & $\begin{array}{l}\text { able1 } \\
\text { luous pre }\end{array}$ & comr & case analysis) & \multirow{6}{*}{$\begin{array}{l}\text { where selection is } \\
\text { achieved through } \\
\text { shrinking regression } \\
\text { coefficients to zero[24, } \\
\text { 25]. So, finally we got a } \\
\text { LASSO model. }\end{array}$} \\
\hline Predictor & coding & Wald $\chi^{2}$ & $d f$ & $p$-value & \\
\hline \multirow[t]{4}{*}{ Age } & Linear & 24.96 & 1 & $<.0001$ & \\
\hline & RCS (3) & 22.03 & 2 & $<.0001$ & \\
\hline & $\operatorname{RCS}(4)$ & 23.90 & 3 & $<.0001$ & \\
\hline & RCS (5) & 23.62 & 4 & 0.0001 & \\
\hline \multirow[t]{4}{*}{ BS } & Linear & 0.61 & 1 & 0.4345 & \multirow{9}{*}{$\begin{array}{l}\text { In order to avoid the } \\
\text { statistically 囚error of } \\
\text { multiple repeated } \\
\text { detection of } \\
\text { interactions[26], we } \\
\text { tested the overall } \\
\text { interactions of Age } \\
\text { with other remaining } \\
\text { predictors[27]; the } \\
\text { same test was also do } \\
\text { for SEX. If there exists } \\
\text { statistical significance }\end{array}$} \\
\hline & RCS (3) & 0.77 & 2 & 0.6798 & \\
\hline & RCS (4) & 5.66 & 3 & 0.1291 & \\
\hline & RCS (5) & 6.39 & 4 & 0.1719 & \\
\hline \multirow[t]{5}{*}{ SC } & Linear & 13.27 & 1 & 0.0003 & \\
\hline & $\operatorname{RCS}(3)$ & 12.77 & 2 & 0.0017 & \\
\hline & $\operatorname{RCS}(4)$ & 13.94 & 3 & 0.0030 & \\
\hline & RCS (5) & 13.96 & 4 & 0.0074 & \\
\hline & Log & 11.25 & 1 & 0.0008 & \\
\hline \multirow[t]{4}{*}{$\mathrm{Hb}$} & Linear & 10.19 & 1 & 0.0014 & \multirow{8}{*}{$\begin{array}{l}\text { as a whole, then } \\
\text { introduce the } \\
\text { statistically significant } \\
\text { interaction terms; } \\
\text { otherwise, the } \\
\text { possibility is excluded. } \\
\text { We also tested the } \\
\text { proportional hazards } \\
\text { assumption. }\end{array}$} \\
\hline & RCS (3) & 15.14 & 2 & 0.0005 & \\
\hline & RCS (4) & 14.65 & 3 & 0.0021 & \\
\hline & RCS (5) & 15.36 & 4 & 0.0040 & \\
\hline \multirow[t]{4}{*}{ ALB } & Linear & 33.97 & 1 & $<.0001$ & \\
\hline & RCS (3) & 31.76 & 2 & $<.0001$ & \\
\hline & RCS (4) & 31.30 & 3 & $<.0001$ & \\
\hline & RCS (5) & 32.07 & 4 & $<.0001$ & \\
\hline $\begin{array}{l}\text { Note: Bold } \\
\text { SUR, were }\end{array}$ & \multicolumn{3}{|c|}{ SUR, were coded as binary variables. } & & $\begin{array}{l}\text { 4. Model } \\
\text { performa }\end{array}$ \\
\hline
\end{tabular}

Overall performance measures Nagelkerke's $\mathrm{R}^{2}$ was presented. The concordance (c) statistic was given as the LASSO model's discrimination measure, which was further illustrated by dividing the predictions in 3 groups, and plotting the Kaplan-Meier curves of each group. 
We did not evaluate calibration, because "assessment of calibration makes little sense in the development data, while it is essential at external validation"[28].

\section{Internal Validation}

Then we assessed internal validity with a bootstrapping procedure of 1000 repetitions for a realistic estimate of the performance of the LASSO and full model in similar future patients.

\section{Results}

\section{Participants}

From January 2015 to December 2020, 923 patients with hip fractures were admitted to our hospital, the final eligible patients were 735. As of the end of the last interview, May 28, 2021, there were 11 patients determined lost to follow-up, and the average follow-up time were 325.6 day per person. The selection process and specific characteristics of sample are shown in the Fig. $\mathbf{3}$ and table 2respectively. 
Table 2

Participants Characteristics

Characteristic
Missing

Values,

$n$ (\%)
Value

\section{Value}

\section{General characteristics}

Mean age(years)

Male

Medical Insurance

Employee Medical Insurance (EMI)

Non-EMI

\section{Fracture-related}

Fracture site

Femoral neck

Intertrochanteric

Subtrochanteric

Fracture type

Primary

Secondary

Fracture to admitted (d)

Admitted to surgery(d)(637patients) \#

Length of stay (LOS)

medical history

Diabetes

Hypertension (HYP)

Malignancy (MLA)

Kidney disease (KD)

Lung disease (LD)

Ability of living independence (ALI) ( $\mathrm{No}=0$, Yes =1)
0

0

0

0

$305(41.5 \%)$

$413(56.2 \%)$

$17(2.3 \%)$

0

$689(93.7 \%)$

$46(6.3 \%)$

2.3(SD, 5.9) (Range, 0-62)

0

5.5(SD, 3.3) (Range, 1-45)

0

13.0(SD, 6.4) (Range, 1-52)
116(15.8\%)

$357(48.6 \%)$

$0 \quad 18(2.4 \%)$

0

$11(1.5 \%)$

$58(7.9 \%)$

271(36.9\%)

107(14.6\%) (No = 0) 


\begin{tabular}{|c|c|c|}
\hline Characteristic & $\begin{array}{l}\text { Missing } \\
\text { Values, } \\
n(\%)\end{array}$ & Value \\
\hline $\begin{array}{l}\text { Cardiovascular and cerebrovascular diseases } \\
\text { (CCD) }\end{array}$ & 0 & $295(40.1 \%)$ \\
\hline \multicolumn{3}{|l|}{ Clinical indicators } \\
\hline Blood sugar (BS)(mmol/L) & $9(1.2 \%)$ & 6.8 (SD 2.4) (Range,3.4-21.6) \\
\hline Serum creatinine $(\mathrm{SC})(\mu \mathrm{mol} / \mathrm{L})^{\star}$ & $9(1.2 \%)$ & $\begin{array}{l}\text { 70.3(SD, 23.8) (Range, 26.0- } \\
\text { 190.8) }\end{array}$ \\
\hline Hemoglobin $(\mathrm{Hb})(\mathrm{g} / \mathrm{L})$ & $9(1.2 \%)$ & $\begin{array}{l}\text { 117.8(SD, 20.1) (Range, 43- } \\
\text { 179) }\end{array}$ \\
\hline Albumin (ALB)(g/L) & $13(1.8 \%)$ & $\begin{array}{l}37.9(\mathrm{SD}, 4.1) \text { (Range, 21.8- } \\
48.2)\end{array}$ \\
\hline Mean arterial pressure (MAP)(mmHg) & 0 & $\begin{array}{l}104.8(S D, 16.2) \text { (Range, 56- } \\
182)\end{array}$ \\
\hline Partial pressure of oxygen $\left(\mathrm{PaO}_{2}\right)(\mathrm{mmHg})$ & $212(28.8 \%)$ & 75.4(SD, 17.4) (Range, 33-176) \\
\hline Total protein $(\mathrm{TP})(\mathrm{g} / \mathrm{L})$ & $16(2.2 \%)$ & $\begin{array}{l}\text { 63.4(SD, 6.8) (Range, 44.6- } \\
\text { 105.0) }\end{array}$ \\
\hline \multicolumn{3}{|l|}{ Treatment } \\
\hline Skeletal traction & 0 & $375(51.0 \%)$ \\
\hline Surgery & $9(1.2 \%)$ & $637(86.7 \%)$ \\
\hline $\begin{array}{l}\text { Note: * means } S C \text { values is winsorized, before } \\
42.6) \text {,the range was }[26.0,860.0] \\
\text { \# means It includes only } 637 \text { patients who hav } \\
\text { SD: standard deviation }\end{array}$ & $\begin{array}{l}\text { disposing, the } \\
\text { erated in our }\end{array}$ & $\begin{array}{l}\text { an was } 72.14 \mu \mathrm{mol} / \mathrm{L}(\mathrm{SD} \text {, } \\
\text { ital. }\end{array}$ \\
\hline
\end{tabular}

\section{Model development}

By performing SI on the raw data, we finally got a no missing value sample with 735 participants and 68 interesting events. The EPV ratio $=68 / 12=5.7$. Admittedly, it was a small sample[15]. Based on this sample, all 12 candidate predictors were used to develop a full model. We also examined the unadjusted association between each predictor and the outcome (Table 3). 
Table 3

Association between each predictor and outcome from SI data set.

\begin{tabular}{|c|c|c|c|c|c|}
\hline Characteristic & $\begin{array}{l}\text { patients with } \\
\text { an } \\
\text { outcome(n = } \\
68)\end{array}$ & $\begin{array}{l}\text { patients } \\
\text { without an } \\
\text { outcome(n = } \\
667)\end{array}$ & $\begin{array}{l}\text { Univariate } \\
\text { hazard } \\
\text { ratios( } 95 \% C l)\end{array}$ & $\begin{array}{l}\text { Full model } \\
\text { hazard } \\
\text { ratios }(95 \% C l)\end{array}$ & $\begin{array}{l}\text { LASSO } \\
\text { model } \\
\text { hazard } \\
\text { ratios }(95 \% \mathrm{Cl})\end{array}$ \\
\hline \multicolumn{6}{|c|}{ Demographic characteristics } \\
\hline $\begin{array}{l}\text { Age(years) (82 } \\
\text { vs 68) }\end{array}$ & $80(S D 7.9)$ & $74(S D 9.5)$ & $2.7(1.8,4.0)$ & $2.2(1.4,3.5)$ & $1.8(1.2,2.8)$ \\
\hline $\begin{array}{l}\text { SEX (Female } \\
=0, \text { Male }=1,1 \\
\text { vs } 0 \text { ) }\end{array}$ & $\begin{array}{l}35(51.5 \%) \\
\text { (Male) }\end{array}$ & $\begin{array}{l}244(36.6 \%) \\
\text { (Male) }\end{array}$ & $1.7(1.1,2.8)$ & $1.7(1.0,2.8)$ & $1.4(0.8,2.2)$ \\
\hline \multicolumn{6}{|l|}{ Medical history } \\
\hline $\begin{array}{l}\mathrm{MLA}(\mathrm{No}=0, \\
\mathrm{Yes}=1, \mathbf{1} \text { vs } 0)\end{array}$ & $5(7.4 \%)(Y e s)$ & 13(1.9\%) (Yes) & $3.2(1.3,7.9)$ & $4.1(1.4,11.9)$ & $2.7(1.0,7.7)$ \\
\hline $\begin{array}{l}\operatorname{LD}(\text { No }=0 \\
\text { Yes }=1, \mathbf{1} \text { vs } 0)\end{array}$ & $\begin{array}{l}34(50.0 \%) \\
\text { (Yes) }\end{array}$ & $\begin{array}{l}266(39.9 \%) \\
\text { (Yes) }\end{array}$ & $1.5(1.0,2.5)$ & $1.0(0.6,1.7)$ & - \\
\hline $\begin{array}{l}\text { ALI (No }=0 \\
\text { Yes }=1,0 \text { vs } 1)\end{array}$ & $\begin{array}{l}15(22.1 \%) \\
\text { (No) }\end{array}$ & $\begin{array}{l}92(13.8 \%) \\
\text { (No) }\end{array}$ & $1.7(0.9,3.0)$ & $1.5(0.8,2.9)$ & $1.3(0.7,2.5)$ \\
\hline $\begin{array}{l}\operatorname{CCD}(\mathrm{No}=0, \\
\mathrm{Yes}=1, \mathbf{1} \text { vs } \mathbf{0})\end{array}$ & $\begin{array}{l}37(54.4 \%) \\
\text { (Yes) }\end{array}$ & $\begin{array}{l}258(38.7 \%) \\
(Y e s)\end{array}$ & $1.8(1.1,3.0)$ & $1.5(0.9,2.6)$ & $1.4(0.8,2.4)$ \\
\hline $\begin{array}{l}\operatorname{HYP}(\mathrm{No}=0, \\
\text { Yes }=1,1 \text { vs } 0)\end{array}$ & $\begin{array}{l}34(50.0 \%) \\
\text { (Yes) }\end{array}$ & $\begin{array}{l}323(48.4 \%) \\
\text { (Yes) }\end{array}$ & $1.1(0.7,1.7)$ & $1.5(0.8,2.5)$ & $1.2(0.7,2.0)$ \\
\hline
\end{tabular}

Clinical indicators

\begin{tabular}{llllll}
$\begin{array}{l}\mathrm{BS}(\mathrm{mmol} / \mathrm{L}) \\
(\mathbf{7 . 1} \text { vs 5.5) }\end{array}$ & $6.9(S D 2.7)$ & $6.8(S D 2.3)$ & $1.0(0.9,1.2)$ & $1.1(0.9,1.2)$ & - \\
$\begin{array}{l}\mathrm{SC}(\mu \mathrm{mol} / \mathrm{L}) \\
(\mathbf{7 9} \text { vs 56) }\end{array}$ & $80.1(S D 32.2)$ & $69.2(S D 22.5)$ & $1.3(1.1,1.6)$ & $1.2(1.0,1.5)$ & $1.2(1.0,1.4)$ \\
$\begin{array}{l}\mathrm{ALB}(\mathrm{g} / \mathrm{L}) \\
(\mathbf{4 0 . 8} \text { vs 35.3) }\end{array}$ & $35.1(S D 4.3)$ & $38.1(S D 4.0)$ & $0.4(0.3,0.6)$ & $0.6(0.4,0.8)$ & $0.6(0.5,0.9)$ \\
$\begin{array}{l}\mathrm{Hb}(\mathrm{g} / \mathrm{L})(\mathbf{1 3 2} \\
\text { vs 104) }\end{array}$ & $\begin{array}{l}111.2(S D \\
23.3)\end{array}$ & $118.4(S D 19.6)$ & $0.6(0.5,0.9)$ & $1.1(0.7,1.5)$ & - \\
\hline
\end{tabular}

Treatment

$\begin{array}{llllll}\text { SUR }(\mathrm{No}=0, & 30(44.1 \%) & 59(8.8 \%)(\mathrm{No}) & 6.9(4.3,11.2) & 5.2(3.1,8.7) & 4.8(2.9,8.0) \\ \text { Yes }=1, \text { 0 vs } 1) & \text { (No) }\end{array}$

Note: $S D$ : standard deviation; $C l$ : confidence interval 
In exploring the optimal coding of five continuous variables, we found that it was suitable for $\mathrm{BS}$ and $\mathrm{Hb}$ adopting nonlinearity (both RCS, 3 knots) while Age, SC, ALB keeping linearity. But we all adopted linear coding when modeling, this is because: $\mathbb{Q}$ In the full model coding $\mathrm{BS}$ and $\mathrm{Hb}$ as nonlinear, neither nonlinear Wald statistics has statistical significance, with $P$ values of 0.834

and 0.088, respectively. And compared with the full linear model (Total Chi-Square 82.01, $12 \mathrm{df}$ ), the nonlinear model (Total Chi-Square $85.23,14 \mathrm{df}$ ) total Wald $\chi 2$ value only increased by 3.22 and with a more $2 \mathrm{df}$. $\nabla$ "In smaller data sets, we may simply have to rely on the additivity assumption to be reasonable"[29]. Nonlinear coding makes the model complex and difficult to interpret, which violates the principle of simplicity. $\otimes$ Using the explained variation $\mathrm{R}^{2}$, we can compare the effects of different encodings of predictors on the model[28]. Compared with the linear full model $\left(R^{2}=0.179\right)$, the $R^{2}$ of nonlinear full model $\left(R^{2}=0.184\right)$ only increases by 0.005 . In view of the above reasons, it is reasonable to use nonlinear coding for $\mathrm{BS}$ and $\mathrm{Hb}$.

Neither Age nor SEX had significantly total interaction with the remaining variables, $p$ values of them were 0.343 and 0.305 , respectively. Therefore, no interaction terms were introduced in the

full model. The coefficients of the full model and the LASSO model, as well as the encoding forms of each variable, can be found in Table 4. The overall test for the proportional hazards assumption of full model was not statistically significant (overall $\chi^{2} 14.1975,12 \mathrm{df}, p=0.288$ ), with a non-proportionality suggested for LD. 
Table 4

Presenting the model, including the baseline survival, for 1-year survival (from SI data set)

The Full Model

\begin{tabular}{|c|c|c|c|c|c|c|}
\hline Predictors & $\stackrel{\beta}{\text { Coefficient }}$ & SE & $p$ value & ${ }_{\text {Coefficient }}^{\beta}$ & SE & $\begin{array}{l}p \\
\text { value }\end{array}$ \\
\hline Age(linear) & 0.0567 & 0.0167 & 0.0007 & 0.0421 & 0.0156 & 0.0070 \\
\hline $\begin{array}{l}\text { SEX }=1(\text { Female }=0 \text {, Male } \\
=1)\end{array}$ & 0.5125 & 0.2591 & 0.0479 & 0.3047 & 0.2567 & 0.2352 \\
\hline $\mathrm{MLA}=1(\mathrm{No}=0, \mathrm{Yes}=1)$ & 1.4137 & 0.5430 & 0.0092 & 1.0000 & 0.5333 & 0.0608 \\
\hline $\mathrm{LD}=1(\mathrm{No}=0, \mathrm{Yes}=1)$ & -0.0083 & 0.2625 & 0.9746 & - & - & - \\
\hline $\mathrm{ALI}=1(\mathrm{No}=0, \mathrm{Yes}=1)$ & -0.4368 & 0.3268 & 0.1813 & -0.2721 & 0.3253 & 0.4028 \\
\hline $\mathrm{CCD}=1(\mathrm{No}=0, \mathrm{Yes}=1)$ & 0.4075 & 0.2781 & 0.1428 & 0.3432 & 0.2754 & 0.2126 \\
\hline $\mathrm{HYP}=1(\mathrm{No}=0, \mathrm{Yes}=1)$ & 0.3837 & 0.2807 & 0.1716 & 0.1713 & 0.2743 & 0.5322 \\
\hline BS (linear) & 0.0350 & 0.0448 & 0.4345 & - & - & - \\
\hline SC (linear) & 0.0091 & 0.0041 & 0.0284 & 0.0080 & 0.0041 & 0.0502 \\
\hline ALB (linear) & -0.1001 & 0.0336 & 0.0029 & -0.0819 & 0.0310 & 0.0082 \\
\hline $\mathrm{Hb}$ (linear) & 0.0020 & 0.0067 & 0.7659 & - & - & - \\
\hline SUR $=1(\mathrm{No}=0, \mathrm{Yes}=1)$ & -1.6523 & 0.2592 & $<.0001$ & -1.5734 & 0.2546 & $<.0001$ \\
\hline
\end{tabular}

Based on the LASSO model, we created a monogram so that 
Table 5

A Simple Scoring System for calculating the survival/mortality

\begin{tabular}{|c|c|c|c|c|c|}
\hline Predictor & Variable Range & $\begin{array}{l}\text { Score } \\
\text { Range }\end{array}$ & $\begin{array}{l}\text { Total } \\
\text { Score }\end{array}$ & Survival & mortality \\
\hline Age (years) & $50-105$ & $0-9.4$ & 15.4 & 0.9 & 0.1 \\
\hline \multirow{2}{*}{$\begin{array}{l}\text { SEX }(\text { Female }=0, \\
\text { Male }=1)\end{array}$} & 0 & 0 & 20 & 0.8 & 0.2 \\
\hline & 1 & 1.3 & 22 & 0.7 & 0.3 \\
\hline \multirow[t]{2}{*}{$\operatorname{MLA}(\mathrm{No}=0, \mathrm{Yes}=1)$} & 0 & 0 & 23 & 0.6 & 0.4 \\
\hline & 1 & 4 & 24.3 & 0.5 & 0.5 \\
\hline \multirow[t]{2}{*}{$\mathrm{ALI}(\mathrm{No}=0, \mathrm{Yes}=1)$} & 0 & 1.1 & 25.5 & 0.4 & 0.6 \\
\hline & 1 & 0 & 26.6 & 0.3 & 0.7 \\
\hline \multirow[t]{2}{*}{$\operatorname{CCD}(\mathrm{No}=0, \mathrm{Yes}=1)$} & 0 & 0 & 27.8 & 0.2 & 0.8 \\
\hline & 1 & 1.4 & 29.2 & 0.1 & 0.9 \\
\hline \multirow[t]{2}{*}{$\operatorname{SUR}((\mathrm{No}=0, \mathrm{Yes}=1)$} & 0 & 6.4 & & & \\
\hline & 1 & 0 & & & \\
\hline $\mathrm{SC}(\mu \mathrm{mol} / \mathrm{L})$ & $20-200$ & $0-5.8$ & & & \\
\hline ALB (g/L) & $20-50$ & $10-0$ & & & \\
\hline \multirow[t]{2}{*}{$\operatorname{HYP}(\mathrm{No}=0, \mathrm{Yes}=1)$} & 0 & 0 & & & \\
\hline & 1 & 0.7 & & & \\
\hline \multicolumn{6}{|c|}{ 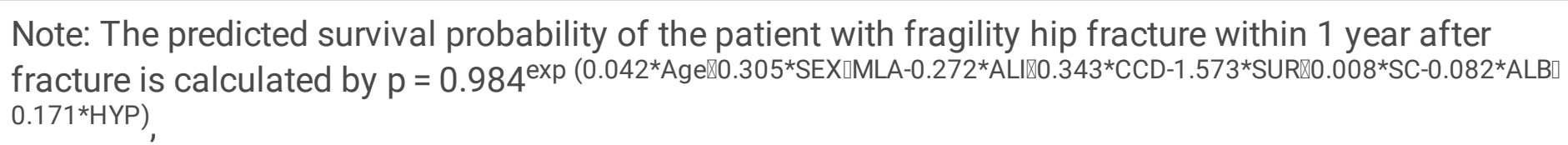 } \\
\hline
\end{tabular}

The corresponding mortality rate is 1 -p. readers can easily apply the model to similar potential patients(Figure 4 and Table 5).

\section{Model performance}

The c statistic of the final LASSO model is 0.814 ( $95 \% \mathrm{CI} 0.762-0.865)$. Discrimination is further illustrated by dividing the predictions into low, middle and high 3 groups, and plotting the Kaplan-Meier curves of each group (Fig. 5). We found that patients in the high-risk group(Ip3) had a considerably poorer chance of survival at 1 year after hip fracture: around $77 \%$. In addition, we also present the overall performance measures $\mathrm{R}^{2}$ and the optimism gained through internal validation of 1000 bootstrap repetitions, so that readers can understand the predictive effectiveness of the model for potential similar patients. The same performance measures for the full model are also presented(Table 6). 
Table 6

Model performance measures

\begin{tabular}{|lllllll|}
\hline & Full model & & \multicolumn{3}{l|}{ LASSO model } \\
\hline $\begin{array}{l}\text { Performance } \\
\text { measures }\end{array}$ & Original & $\begin{array}{l}\text { Internal } \\
\text { validation(B } \\
1000)\end{array}$ & Optimism & Original & $\begin{array}{l}\text { Internal } \\
\text { validation(B } \\
=1000)\end{array}$ & Optimism \\
\hline $\mathrm{C}$ & 0.816 & 0.790 & 0.026 & 0.814 & 0.795 & 0.019 \\
\hline R2 & 0.188 & 0.147 & 0.041 & 0.187 & 0.158 & 0.030 \\
\hline
\end{tabular}

\section{Discussion}

\section{Limitations}

This study has the following limitations. First, the biggest

shortcoming is the lower effective sample size, EPV is less than 6(5.7

events per variable) and the total interesting events less than 100 . This more or less affects the stability of the LASSO model and usually lead to over-fitting and optimism, although we try to compensate for these shortcomings from the methodology. Second, because the LASSO models derived from each of MI data sets have not been easily synthesized with an efficient way, the MI was not used for the missing data. This made the estimation of the model fail to fully consider the uncertainty of the inference of missing values. Third, in order to increase EPV ratio, the number of candidate predictors was reduced as much as possible. This resulted in other indicators related to survival proved by studies, such as, time to surgery[30-35] ,time from trauma to operation[36, 37], patient's financial situation[38], fracture sites[39, 40], fracture season[41], etc. not being included in the model. The calibrated R2(0.158) also confirms that there is still much variability which cannot be explained by the model. Fourth, the design of this paper was a retrospective cohort study. Compared with an ideal prospective cohort study, the collection of various values cannot be controlled in advance. This results in the accuracy of the data somewhat inadequate, thus affecting the credibility of the model prediction. Fifth, the representativeness of the sample is insufficient. Most of the patients in this sample are rural patients (approximately $80 \%$ of the sample size, but urban population about 64\% in 2021 in China), which might affect the applicability, and generalizability of the model. Finally, this study only conducted internal validation. Although the results show that the performance of the model is acceptable, in view of the above-mentioned shortcomings, external validation is obviously necessary.

\section{Interpretation}

Unlike the models of Elliott 2003[5] and Anita2009[4], we avoided using various scoring models as predictors to keep the model simple and easy for clinical use. Different from the Maxwell 2008[6] model, 
we avoided converting numerical variables into categorical variables on the basis of ensuring the stability of variable values, to improve the utilization of valuable data. We used very common preoperative variables that can be quickly obtained after patients hospitalized to predict the 1-year survival of them. Our final model has no non-linear coding and interaction terms, and only contains 9 covariates, including age, gender, history of malignant tumors, self-care ability before fracture, history of cardiovascular and cerebrovascular diseases, history of hypertension, whether to choose surgery, blood creatinine value and albumin value at admission. So, we have achieved the goal of developing a simple model to guide doctors and patients to rationally choose treatment methods. Admittedly, whether the predictive model is practical needs the subsequent clinical feedback, but its simplicity has laid a good foundation for practicality.

This may be the first survival prognosis model for fragile hip fracture developed for Chinese subjects. The multivariate regression analysis of our LASSO model shows that age, serum albumin value at admission and whether to choose surgery are effective predictors for 1-year survival rate, consistent with the results of many studies(Fig.6) [9, 31, 34, 42-44]. In the full model without shrinkage to the coefficients, in addition to the above three predictors, gender, history of malignant tumors and creatinine value at admission are also valid predictors. The prognostic validity of these three variables is basically the conclusion of most studies[31, 34, 39, 42, 43, 45-47]. This difference between the two models stem from the fact that the effect strength between the latter three predictors and the outcome is weaker than that of the first three. The patient's blood pressure, blood sugar, hemoglobin, lung disease, self-care ability before fracture, and history of cardiovascular and cerebrovascular disease are not significantly related to the1year survival rate. However, many studies[33, 37, 43, 46, 48-50] have shown that lung disease, preoperative walking ability were related to postoperative mortality of hip fractures. The reasons for this difference may include: the study population was different, most of the research subjects were only limited to patients treated by surgery; the age range is different, most of which were patients over 65 years old; and the race of participants was different.

The discrimination c value for the final LASSO model is 0.814 (95\% $\mathrm{Cl} 0.762-0.865)$, located between an intermediate accuracy range (0.71-0.90), so the discriminative ability of the model is acceptable. After correcting the optimism through internal validation, the $c$ value was reduced from 0.814 to 0.795 , a decrease of 0.019 , which is still acceptable. Similar results are also seen in the full model performance evaluation. In contrast with the full model, the LASSO model decreased in optimism (from 0.026 to 0.019). These results prove that it is reasonable to use the LASSO method for model estimation based on the full model under the condition of a small sample. Similar results are also seen in Overall Performance Measure $\mathrm{R}^{2}$.

\section{Implications}

The applicable objects of this model are patients with fragile hip fractures. Obviously, it is not applicable to patients with non-fragility fractures. Because this model is simple and clear, in addition to orthopedic surgeons, patients and their family members can also easily grasp the model. The optimal application environment are these general hospitals with non-urban population as the main patients. The next of 
external validation can be a general hospital with urban population as the main patients. Limited by sample size, this model does not consider much more variables. It is recommended to include more relevant predictors in future model update studies.

\section{Conclusion}

Using the SFHF model, doctors can quickly classify patients with fragile hip fractures into low-, medium-, and high-risk patients. On this basis, the treatment plan can be more reasonably determined together with the patients and their families. When a patient be assessed as high risk, and surgery may not effectively improve the survival rate, conservative treatment may be more beneficial for her/him. It is believed that the use of this model has a positive effect on avoiding doctor-patient conflicts.

\section{Abbreviations}

LASSO: least absolute shrinkage and selection operator; SFHF: survival in patients with Fragile Hip Fracture; SUR: surgery, Age: age; ALB: albumin; SEX: sex; SC: serum creatinine; MAL: malignancy; HYP: hypertension; ALI: the ability of living independence; CCD: cardiovascular and cerebrovascular diseases; LOS: length of stay; $\mathrm{PaO}_{2}$ : partial pressure of oxygen; TP: total protein; EPV: events per variable; Y: death; SI: single imputation; MI: multiple imputation; RCS囚restricted cubic splines; df: degrees of freedom; SD: standard deviation; $\mathrm{Cl}$ : confidence interval;

\section{Declarations}

\section{Ethics approval and consent to participate}

This research program was approved by the Medical Ethics Committee of Fenyang Hospital of Shanxi Province. Approved by the ethics committee, this research was free of informed consent.

\section{Consent for publication}

Not applicable

\section{Availability of data and materials}

The datasets used during the current study are available from the corresponding author on reasonable request.

\section{Competing interests}

The authors declare that they have no competing interests. 


\section{Funding}

This research did not receive any funding.

\section{Authors' contributions}

QL guided all processes of the research. HF was the main person in charge and executor of the research, and the manuscript writer. BL was responsible for the professional knowledge support for clinical related issues. XQ and WQ were responsible for data screening, collection, verification and follow-up. All authors read and approved the final manuscript.

\section{Acknowledgements}

Special thanks to Chu Zheng for statistical assistance and supporting paper writing and publication; also thank Luyang Yang for supporting paper writing and publication; thank Jia Zhang, Zhijie Hou, Yanrong Wang, Jinzhen Xia and Xiang Zhen for their help in data verification and patient's follow-up.

\section{References}

1. Sanz-Reig J, Salvador Marín J, Ferrández Martínez J, et al. Prognostic factors and predictive model for in-hospital mortality following hip fractures in the elderly. Chin J Traumatol. 2018;21:163-9. https://doi.org/10.1016/j.cjtee.2017.10.006.

2. Niessen R, Bihin B, Gourdin M, et al. Prediction of postoperative mortality in elderly patient with hip fractures: a single-centre, retrospective cohort study. BMC Anesthesiol. 2018;18:183. https://doi.org/10.1186/s12871-018-0646-x.

3. Jiang HX, Majumdar SR, Dick DA, et al. Development and initial validation of a risk score for predicting in-hospital and 1-year mortality in patients with hip fractures. J Bone Miner Res. 2005;20:494-500. https://doi.org/10.1359/JBMR.041133.

4. Söderqvist A, Ekström W, Ponzer S, et al. Prediction of mortality in elderly patients with hip fractures: a two-year prospective study of 1,944 patients. Gerontology. 2009;55:496-504. https://doi.org/10.1159/000230587.

5. Elliott J, Beringer $T$, Kee F, et al. Predicting survival after treatment for fracture of the proximal femur and the effect of delays to surgery. J Clin Epidemiol. 2003;56:788-95. https://doi.org/10.1016/s0895-4356(03)00129-x.

6. Maxwell MJ, Moran CG, Moppett IK. Development and validation of a preoperative scoring system to predict 30 day mortality in patients undergoing hip fracture surgery. $\mathrm{Br} \mathrm{J}$ Anaesth. 2008;101:511-7. https://doi.org/10.1093/bja/aen236.

7. Moppett IK, Parker M, Griffiths R, et al. Nottingham Hip Fracture Score: Iongitudinal and multiassessment. Br J Anaesth. 2012;109:546-50. https://doi.org/10.1093/bja/aes187. 
8. Moons KGM, Altman DG, Reitsma JB, et al. Transparent Reporting of a multivariable prediction model for Individual Prognosis or Diagnosis (TRIPOD): explanation and elaboration. Ann Intern Med. 2015;162:W1.

9. Aldebeyan S, Nooh A, Aoude A, et al. Hypoalbuminaemia-a marker of malnutrition and predictor of postoperative complications and mortality after hip fractures. Injury. 2017;48:436-40. https://doi.org/10.1016/j.injury.2016.12.016.

10. Ko Y, Baek SH, Ha YC. Predictive factors associated with mortality in Korean elderly patients with hip fractures. J Orthop Surg (Hong Kong). 2019;27:2309499019847848. https://doi.org/10.1177/2309499019847848.

11. Ogundimu EO, Altman DG, Collins GS. Adequate sample size for developing prediction models is not simply related to events per variable. J Clin Epidemiol. 2016;76:175-82. https://doi.org/10.1016/j.jclinepi.2016.02.031.

12. Riley RD, Snell KI, Ensor J, et al. Minimum sample size for developing a multivariable prediction model: PART II - binary and time-to-event outcomes. Stat Med. 2019;38:1276-96. https://doi.org/10.1002/sim.7992.

13. Vittinghoff E, McCulloch CE. Relaxing the rule of ten events per variable in logistic and Cox regression. Am J Epidemiol. 2007;165:710-8. https://doi.org/10.1093/aje/kwk052.

14. Steyerberg EW, Bleeker SE, Moll HA, et al. Internal and external validation of predictive models: a simulation study of bias and precision in small samples. J Clin Epidemiol. 2003;56:441-7. https://doi.org/10.1016/s0895-4356(03)00047-7.

15. Steyerberg EW, Eijkemans MJC, Harrell Jr FE, et al. Prognostic modelling with logistic regression analysis: a comparison of selection and estimation methods in small data sets. Statistics in MedicineStatistics in MedicineStatistics in Medicine. 2000;19:1059. https://doi.org/https://doi.org/10.1002/(SICl)1097-0258(20000430)19:8<1059::AIDSIM412>3.0.CO;2-0.

16. Steyerberg EW. Missing values. Clinical Prediction Models.; 2019.

17. Schomaker M, Heumann C. Bootstrap inference when using multiple imputation. Stat Med. 2018;37:2252.

18. Steyerberg EW. Case Study on Survival Analysis: Prediction of Cardiovascular Events. Clinical Prediction Models; 2019.

19. Schafer JL, Olsen MK. Multiple Imputation for Multivariate Missing-Data Problems: A Data Analyst's Perspective. Multivariate Behav Res. 1998;33:545-71. https://doi.org/10.1207/s15327906mbr3304_5.

20. Sinharay S, Stern HS, Russell D. The use of multiple imputation for the analysis of missing data. Psychol Methods. 2001;6:317. https://doi.org/10.1037/1082-989X.6.4.317.

21. Schafer JL, Graham JW. Missing data: our view of the state of the art. Psychol Methods. 2002;7:147-77. 
22. Harrell FE Jr, Lee KL, Califf RM, et al. Regression modelling strategies for improved prognostic prediction. Statistics in MedicineStatistics in MedicineStatistics in Medicine. 1984;3:143. https://doi.org/https://doi.org/10.1002/sim.4780030207.

23. Steyerberg EW, Eijkemans MJC, Harrell FE Jr, et al. Prognostic modeling with logistic regression analysis: in search of a sensible strategy in small data sets. Med Decis Making. 2001;21:45.

24. Statistical learning with. sparsity: the lasso and generalizations. Chapman and Hall/CRC; 2019.

25. Steyerberg EW. Modern estimation methods. Clinical Prediction Models.,2019.

26. Bedogni G, TSYBAKOV AB, Berlin S. Clinical prediction models-a practical approach to development, validation and updating. Development. 2009;18:53.

27. Regression modeling strategies. with applications to linear models, logistic and ordinal regression, and survival analysis. springer; 2015.

28. Steyerberg EW. Evaluation of performance. Clinical prediction models.,2019.

29. Steyerberg EW. Assumptions in regression models: additivity and linearity. Clinical Prediction Models; 2019.

30. Belmont PJ, E'Stephan JG, Romano D, et al. Risk factors for complications and in-hospital mortality following hip fractures: a study using the National Trauma Data Bank. Arch Orthop Trauma Surg. 2014;134:597.

31. Chow SK, Qin JH, Wong RM, et al. One-year mortality in displaced intracapsular hip fractures and associated risk: a report of Chinese-based fragility fracture registry. J Orthop Surg Res. 2018;13:235. https://doi.org/10.1186/s13018-018-0936-5.

32. Griffiths EJ, Cash DJ, Kalra S, et al. Time to surgery and 30-day morbidity and mortality of periprosthetic hip fractures. Injury. 2013;44:1949-52. https://doi.org/10.1016/j.injury.2013.03.008.

33. Gurger M. Factors impacting 1-year mortality after hip fractures in elderly patients: A retrospective clinical study. Niger J Clin Pract. 2019;22:648-51. https://doi.org/10.4103/njcp.njcp_327_18.

34. Sarabia-Cobo CM, Sáenz-Jalón M, Vélez-Carrera B, et al. Variables to Predict Mortality in Hip Fractures in Patients Over 65 Years of Age: A Study on the Role of Anticoagulation as a Risk Factor. J Trauma Nurs. 2017;24:326-34. https://doi.org/10.1097/JTN.0000000000000313.

35. Trpeski S, Kaftandziev I, Kjaev A. The effects of time-to-surgery on mortality in elderly patients following hip fractures. Pril (Makedon Akad Nauk Umet Odd Med Nauki). 2013;34:115-21.

36. Kim JW, Kim DH, Jang EC, et al. Mortality and its risk factors in nonagenarians after hip fractures. J Orthop Sci. 2019;24:850-4. https://doi.org/10.1016/j.jos.2019.02.019.

37. Pitto RP. The mortality and social prognosis of hip fractures. A prospective multifactorial study. Int Orthop. 1994;18:109-13. https://doi.org/10.1007/BF02484420.

38. Petrelli A, De Luca G, Landriscina T, et al. Effect of Socioeconomic Status on Surgery Waiting Times and Mortality After Hip Fractures in Italy. J Healthc Qual. 2018;40:209-16. https://doi.org/10.1097/JHQ.0000000000000091. 
39. Epstein RS. Hip fractures in the elderly. How to reduce morbidity and mortality. Postgrad Med. 1988;84:254-7. https://doi.org/10.1080/00325481.1988.11700352. 260.

40. Keene GS, Parker MJ, Pryor GA. Mortality and morbidity after hip fractures. BMJ. 1993;307:1248-50. https://doi.org/10.1136/bmj.307.6914.1248.

41. Johansen A, Grose C, Havelock W. Hip fractures in the winter - Using the National Hip Fracture Database to examine seasonal variation in incidence and mortality. Injury. 2020;51:1011-4. https://doi.org/10.1016/j.injury.2020.02.088.

42. Amrayev S, AbuJazar U, Stucinskas J, et al. Outcomes and mortality after hip fractures treated in Kazakhstan. Hip Int. 2018;28:205-9. https://doi.org/10.1177/1120700018773395.

43. Yombi JC, Putineanu DC, Cornu O, et al. Low haemoglobin at admission is associated with mortality after hip fractures in elderly patients. Bone Joint J. 2019;101-B:1122-8. https://doi.org/10.1302/0301-620X.101B9.BJJ-2019-0526.R1.

44. Oztürk A, Ozkan Y, Akgöz S, et al. The risk factors for mortality in elderly patients with hip fractures: postoperative one-year results. Singapore Med J. 2010;51:137-43.

45. Belmont PJ Jr, Garcia EJ, Romano D, et al. Risk factors for complications and in-hospital mortality following hip fractures: a study using the National Trauma Data Bank. Arch Orthop Trauma Surg. 2014;134:597-604. https://doi.org/10.1007/s00402-014-1959-y.

46. Chariyalertsak S, Suriyawongpisal $P$, Thakkinstain A. Mortality after hip fractures in Thailand. Int Orthop. 2001;25:294-7. https://doi.org/10.1007/s002640100270.

47. Paruk F, Matthews G, Gregson CL, et al. Hip fractures in South Africa: mortality outcomes over 12 months post-fracture. Arch Osteoporos. 2020;15:76. https://doi.org/10.1007/s11657-020-00741-4.

48. Traven SA, Reeves RA, Althoff AD, et al. New Five-Factor Modified Frailty Index Predicts Morbidity and Mortality in Geriatric Hip Fractures. J Orthop Trauma. 2019;33:319-23. https://doi.org/10.1097/BOT.0000000000001455.

49. Oztürk I, Toker S, Ertürer E, et al. Analysis of risk factors affecting mortality in elderly patients (aged over 65 years) operated on for hip fractures. Acta Orthop Traumatol Turc. 2008;42:16.

50. Bombaci $\mathrm{H}$, Erdoğan Ö, Çetinkaya $\mathrm{F}$, et al. Preoperative indicators affecting postoperative mortality in elderly patients with hip fractures. Acta Orthop Traumatol Turc. 2012;46:425-9. https://doi.org/10.3944/aott.2012.2829.

\section{Figures}




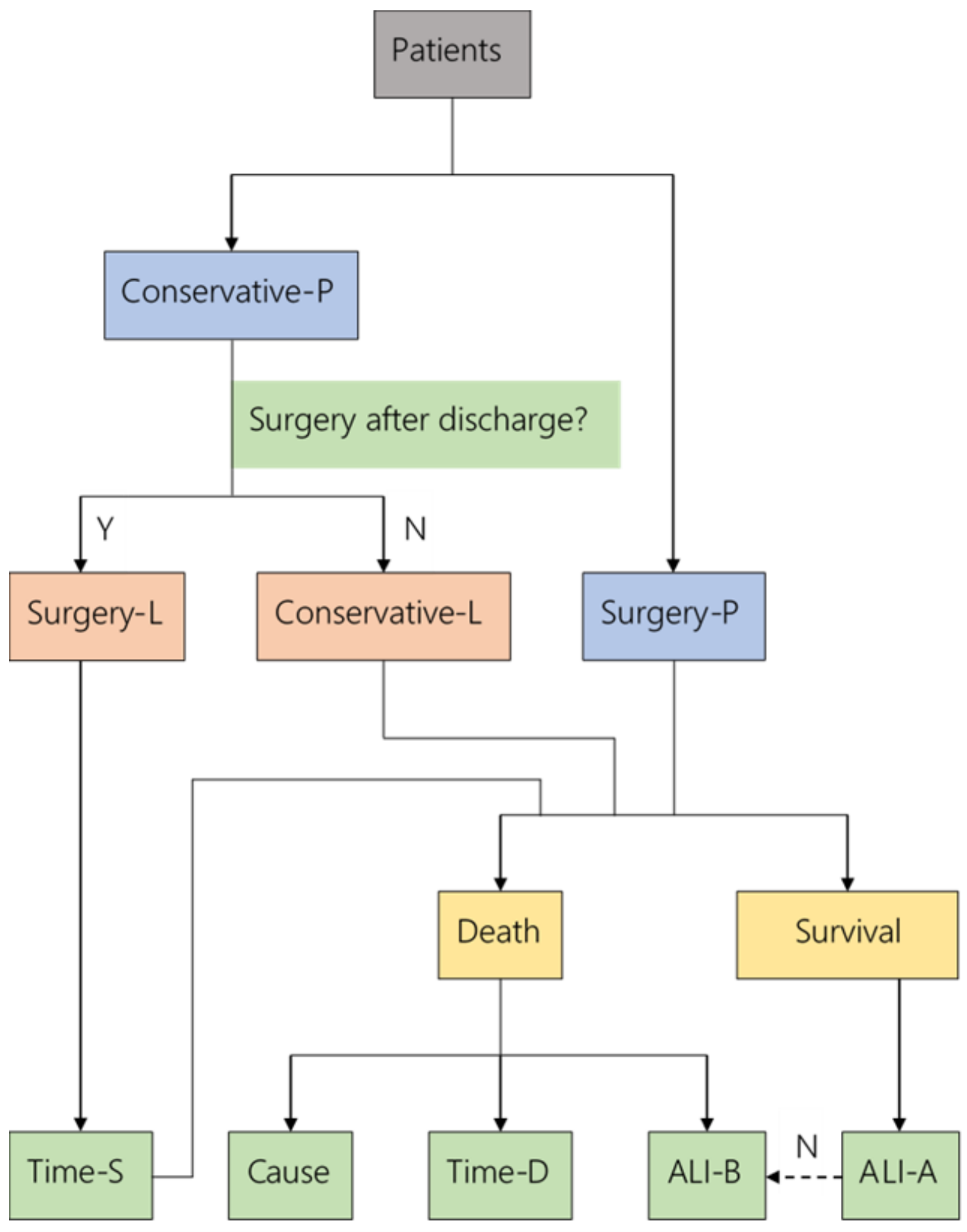

Figure 1

Telephone interview flow chart (Note: -P: primary; -L: last; -S: surgery; -D: death; Y: yes; N: no; Dotted arrow: performed only if ALI-A be no) 


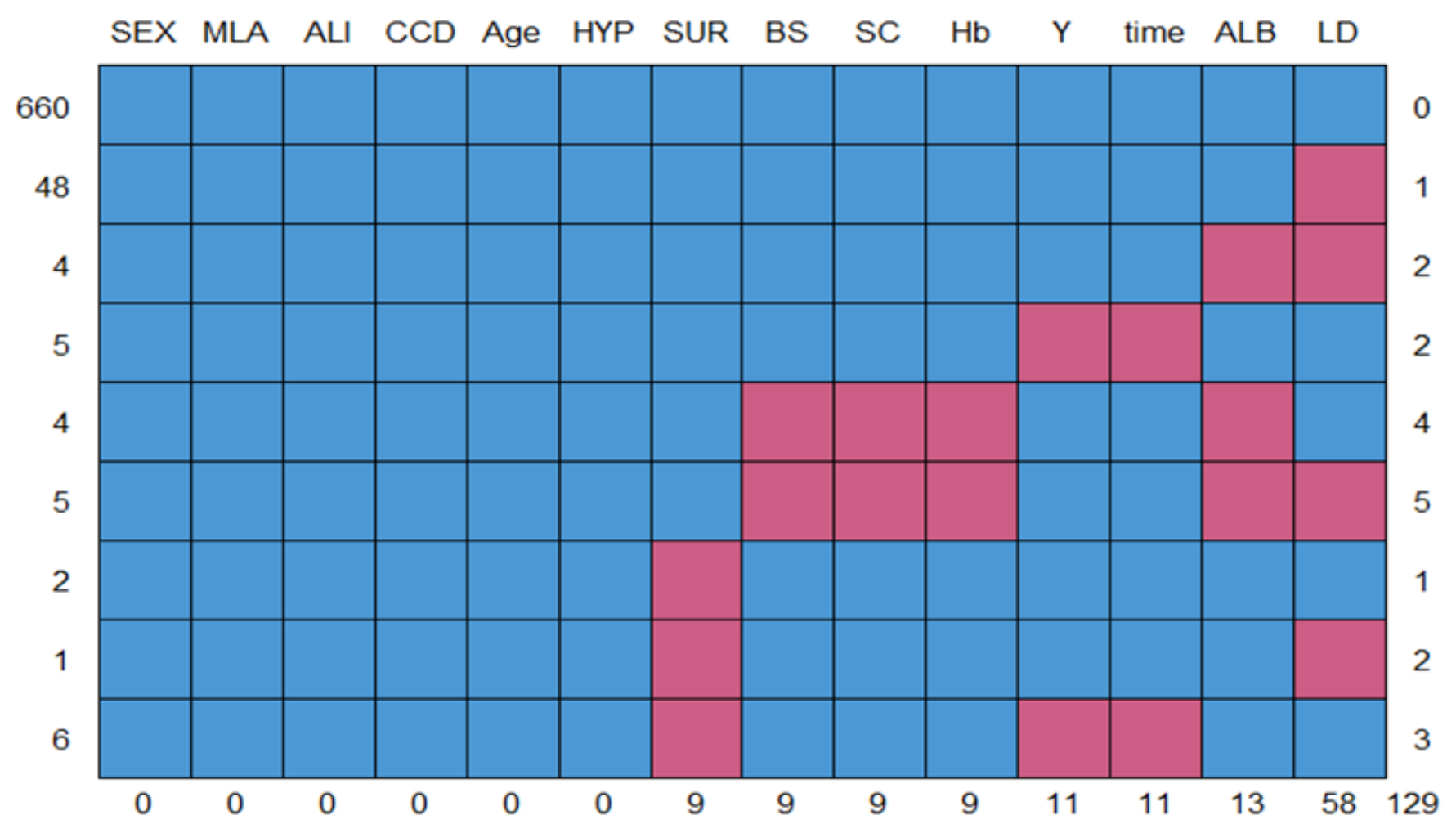

\section{Figure 2}

The characteristics of missing data Note: Blue means no missing, red means missing. The label above the graph represents candidate predictors, the below represents the missing number of each candidate predictor, the left represents the number of observations with the same missing pattern, the right represents the number of types with missing predictors. For instance, ALB predictor has 13 missing values. There are 4 observations missing both ALB and LD. 


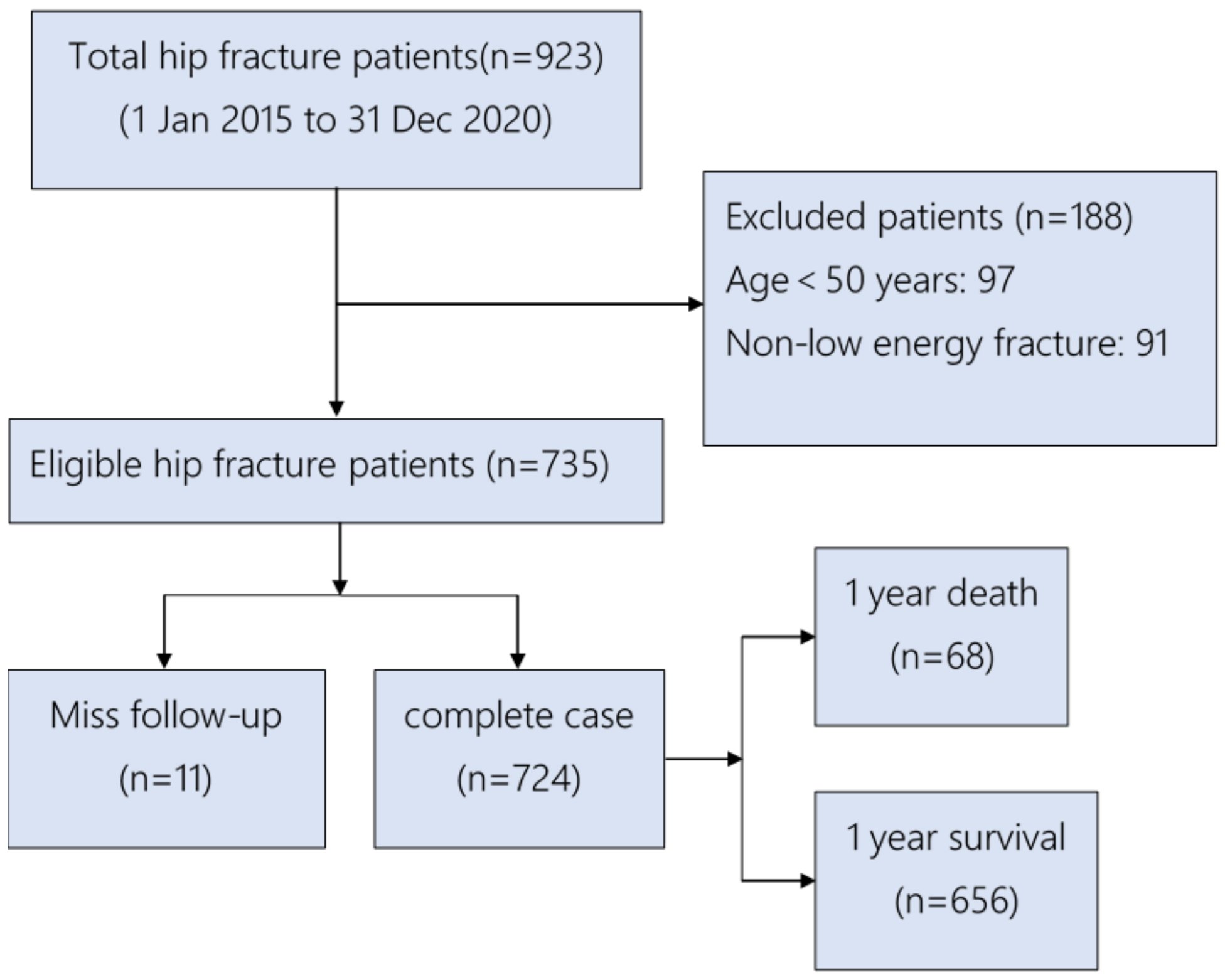

Figure 3

Participant flow diagram 
Points

Age

SEX

MLA

ALI

CCD

SUR

SC

ALB

HYP

Total Points

Linear Predictor

1-year survival
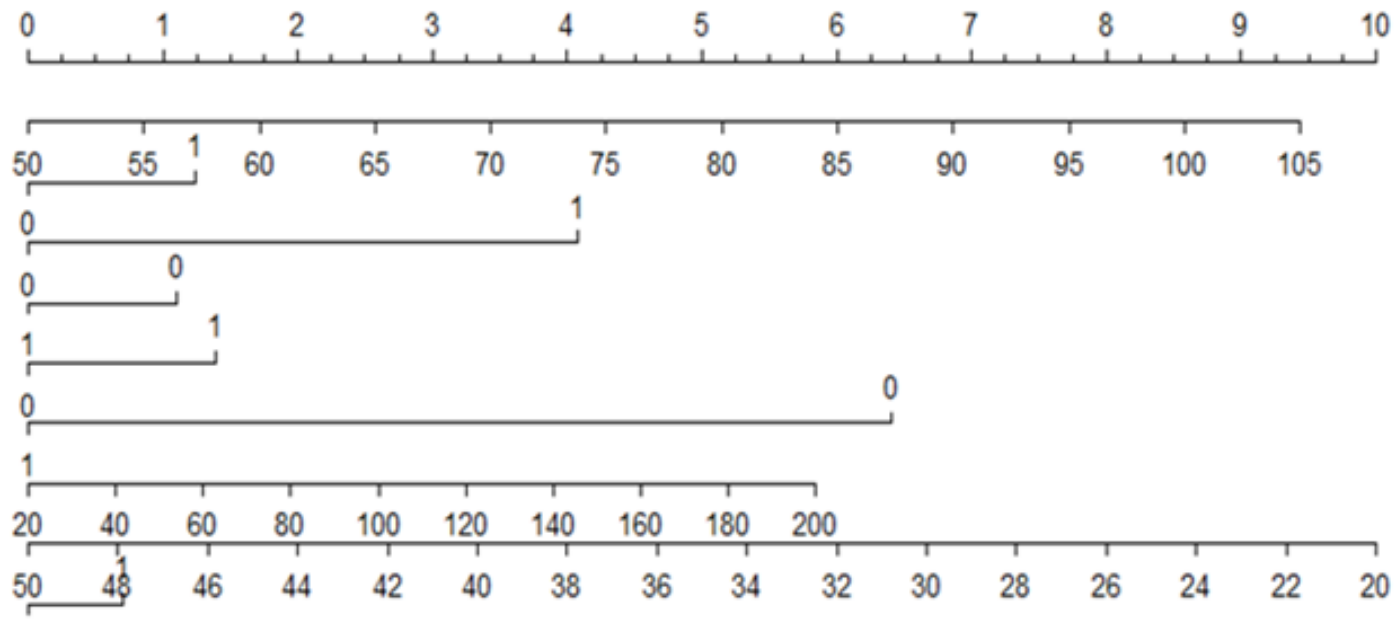

0

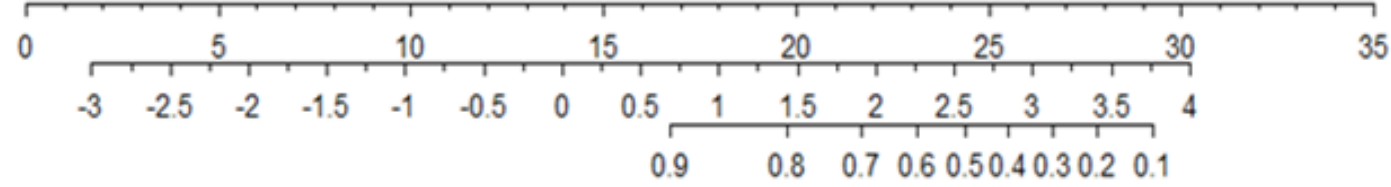

\section{Figure 4}

Nomogram based on the LASSO model. Note: For example, a man (SEX=1.3) with fragility hip fracture, 80 years old $(A g e=5.1)$, no malignant tumor $(M L A=0)$, self-care ability well $(A L I=0)$, have cerebral infarction history $(C C D=1.4)$ and no hypertension $(H Y P=0)$, serum creatinine $100 \mu \mathrm{mol} / \mathrm{L}(\mathrm{SC}=2.6)$, albumin $42 \mathrm{~g} / \mathrm{L}(\mathrm{ALB}=2.7)$, and choose conservative treatment (SUR=6.4), so the total score $=19.5$, the 1-year survival close to 0.8 or $80 \%$, The corresponding 1 -year mortality is $20 \%$. 


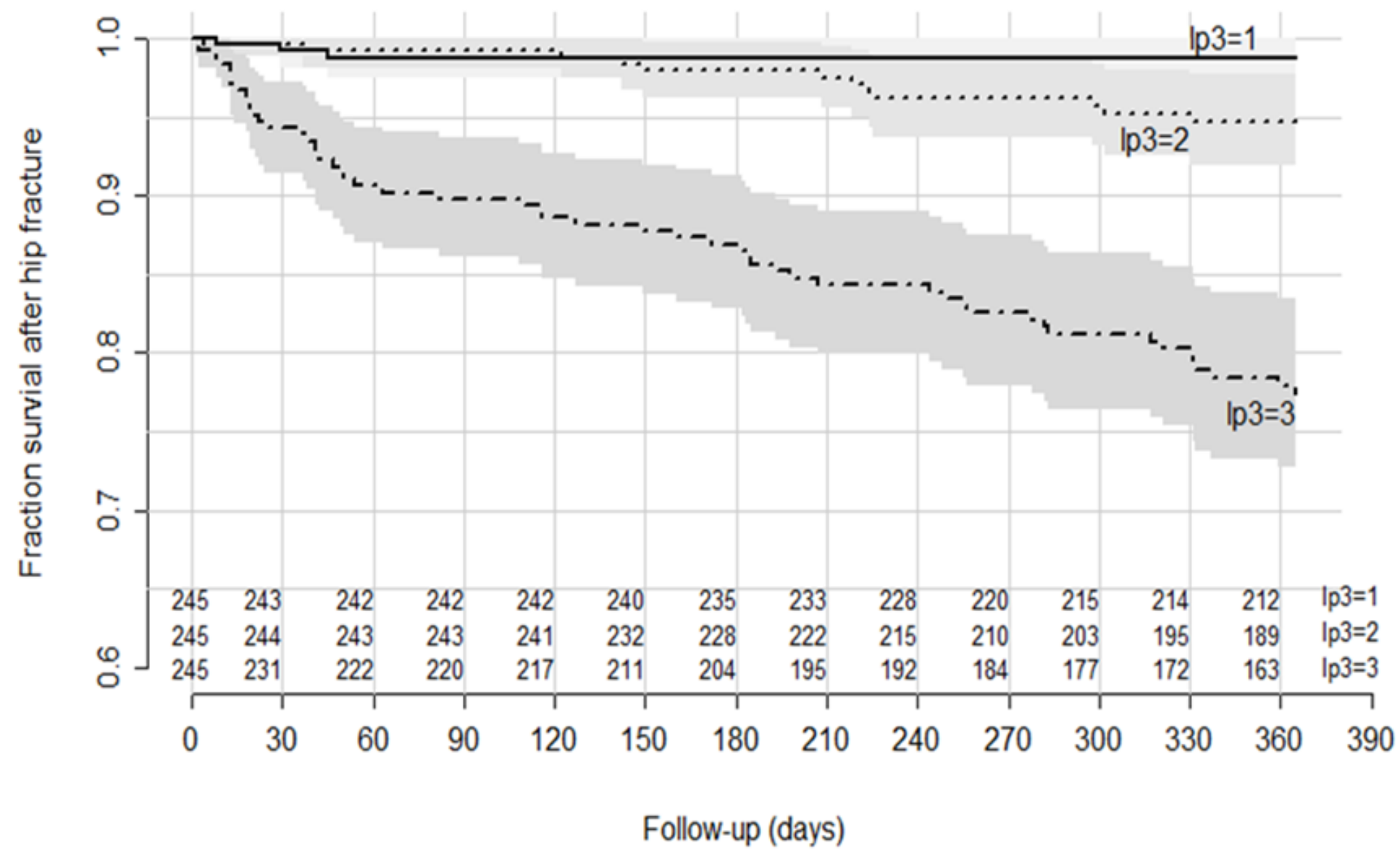

Figure 5

Kaplan-Meier curves for 3 risk groups of low, middle and high. 


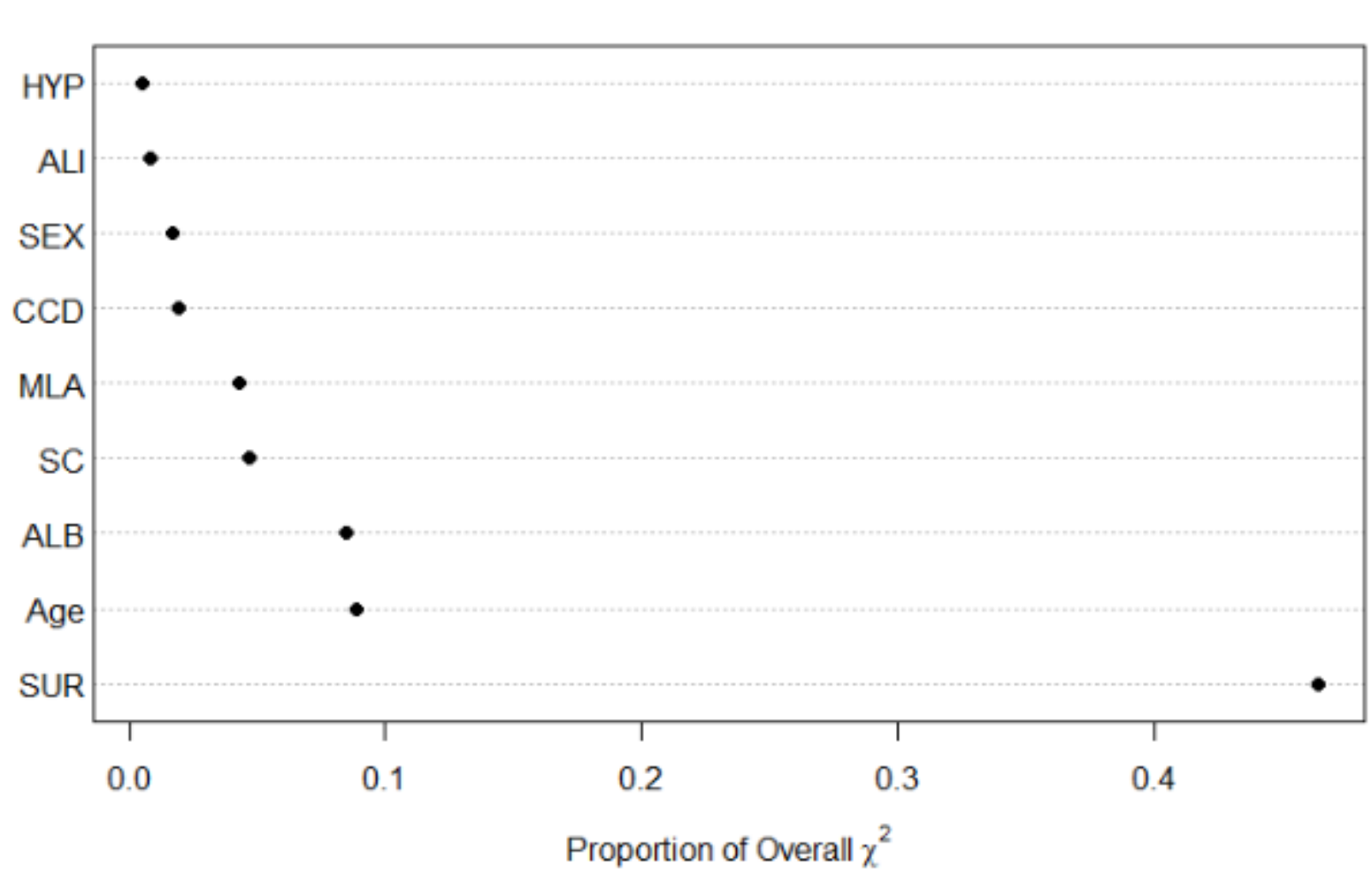

$\chi^{2} \mathrm{P}$

0.40 .5322

0.70 .4028

1.40 .2352

$1.6 \quad 0.2126$

3.50 .0608

3.80 .0502

7.00 .0082

7.30 .0070

38.20 .0000

Figure 6

Relative contribution of each predictor to the full LASSO prediction model 